\title{
Central Oxytocin, Vasopressin, and Corticotropin-Releasing Factor Receptor Densities in the Basal Forebrain Predict Isolation Potentiated Startle in Rats
}

\author{
Hemanth P. Nair, Alisa R. Gutman, Michael Davis, and Larry J. Young \\ Center for Behavioral Neuroscience, Department of Psychiatry and Behavioral Sciences, Yerkes National Primate Research Center, Emory University, \\ Atlanta, Georgia 30329
}

\begin{abstract}
Individual differences in resiliency to particular stressors may be mediated by specific neuropeptide receptor patterns in the brain. Here, we explored this issue by using a multivariate approach to identify brain sites in which oxytocin (OTR), vasopressin (V1aR), and corticotropin-releasing factor type 1 (CRF1) or type 2 receptor binding covaried with a measure of isolation-induced anxiety: isolation potentiated startle (IPS). Partial least squares (PLS) analysis identified three binding sites, the shell of the nucleus accumbens (AccSh), lateral bed nucleus of the stria terminalis, and intermediate zone of the lateral septum, in which CRF1, V1aR, and OTR receptors, respectively, covaried with IPS. Multiple regression analysis demonstrated that the three binding sites accounted for more of the variation in IPS as a linear combination than when considered individually. Using the same multiple regression model, the linear combination of the same three binding sites/peptide receptors measured in a new group of animals successfully predicted their IPS values. There were no differences in binding between grouped and isolated animals, suggesting that the patterns are trait effects rather than a consequence of isolation. Based on the finding that CRF1 receptors in the AccSh were positively correlated with IPS, we infused CRF directly into the AccSh and found that it significantly potentiated startle after a short isolation period but not under grouped conditions. This result directly supported the predictions made by the combined PLS/regression approach. These results suggest that the integrated activity of neuropeptide systems mediating both social behavior and anxiety underlie IPS.
\end{abstract}

Key words: oxytocin; vasopressin; corticotropin-releasing factor; startle; social support; anxiety

\section{Introduction}

Social contact plays an integral role in psychological and physiological well-being for several species. In humans, social support reduces cardiovascular reactivity to acute psychological stress, impacts catecholaminergic activity, and is associated with better immune system function (Uchino and Garvey, 1997). Social isolation increases the risk for depression (Watanabe et al., 2004) and coronary heart disease (Berkman, 1995). In particular rodent species such as rats, group housing lowers cardiovascular, neuroendocrine, and behavioral stress responses (Ruis et al., 1999; Sharp et al., 2002; Andrade and Guimaraes, 2003; Haller et al., 2003).

It is not necessarily the case, however, that all individuals react the same way to isolation or need social support to cope with traumatic situations. For example, in this study, we show that rats

Received Jan. 13, 2005; revised 0ct. 20, 2005; accepted 0ct. 23, 2005.

This work was supported by National Institutes of Mental Health Grants MH06651 (H.P.N.), MH 47840, MH58922, MH52384, and MH59906 (M.D.), and MH 56539, MH56897, and MH64692-01 (L.J.Y.) and by the National Science Foundation Science and Technology Center (the Center for Behavioral Neuroscience of the National Science Foundation under agreement number IBN-9876754). We thank Dr. Lisa Stanek for her assistance with technical aspects of the experiments.

Correspondence should be addressed to Hemanth P. Nair, Center for Behavioral Neuroscience, Department of Psychiatry and Behavioral Sciences, Emory University, 954 Gatewood Road NE, Room 5226, Atlanta, GA 30329. E-mail: hnair@emory.edu.

DOI:10.1523/JNEUROSCI.2524-05.2005

Copyright $\odot 2005$ Society for Neuroscience $\quad 0270-6474 / 05 / 2511479-10 \$ 15.00 / 0$ demonstrate substantial individual variation in isolation potentiated startle (IPS) (the difference in acoustic startle amplitude before and after 3 weeks of isolation). Such individual differences may be mediated by different biological factors. Given that neuropeptide receptor systems demonstrate remarkable individual (Phelps et al., 2002) and species differences (Young et al., 1997; Lim et al., 2005) in their binding and distribution, vulnerability to particular stressors such as social isolation could be linked to genetic differences in their expression patterns. Furthermore, expression patterns involving multiple neuropeptide systems could be a better predictor of individual variation than any single system.

Here, we used a discovery-based technique to identify neuropeptide receptor patterns that covary with isolation potentiated startle. We chose four candidate receptors to include in the analysis: vasopressin (V1aR), oxytocin (OTR), and corticotropin-releasing factor type 1 (CRF1) and type 2 (CRF2). We chose these receptors because species differences in complex social behavior have been linked to vasopressin (AVP) and oxytocin (OXT) (Young et al., 1998a; Goodson and Bass, 2001; Young and Wang, 2004), and stress, anxiety, and regulation of the hypothalamic-pituitary axis are linked to the CRF system and its receptors (Nemeroff, 1988; Dunn and Berridge, 1990; Liang et al., 1992).

A multivariate extension of correlational analysis, partial least 
squares (PLS), was used to identify where, among 13 binding sites in the septum, extended amygdala, accumbens, and cingulate cortex (Cg), OTR, V1aR, CRF1, or CRF2 receptor binding demonstrated the strongest covariance with IPS. We then used multiple regression analysis to test whether the selected regions/peptides accounted for more of the variation in IPS as a combination than individually. A novel and unpredicted finding of this analysis was that CRF1 receptors in the accumbens shell (AccSh) were positively correlated with IPS. We therefore tested whether infusion of CRF into the AccSh could potentiate startle and whether this effect interacted with grouped versus isolated housing.

\section{Materials and Methods}

\section{Subjects}

Male Sprague Dawley rats, $250 \mathrm{~g}$, obtained from Charles River Laboratories (Raleigh, NC) were used for all experiments. Animals were acclimated for 1 week in the vivarium before pretesting. All animals, whether grouped or individually housed, were housed in $45 \times 24 \times 20 \mathrm{~cm}$ polycarbonate cages, maintained on a $12 \mathrm{~h}$ light/dark cycle (lights on at 8:00 A.M.), and given food and water ad libitum. On arrival to our vivarium, animals were housed in groups of four for 1.5-2 weeks before testing. All animals were group housed by the breeder before being sent to our facilities. All animals were treated in compliance with the current rules and standards of the Emory University Institutional Animal Care and Use Committee.

\section{Apparatus}

The apparatus used to measure the startle response has been described in detail previously (Cassella and Davis, 1986). Briefly, four stabilimeter devices are housed in separate sound-attenuated chambers. The stabilimeter consists of a Plexiglas and wire mesh cage suspended between compression springs in a heavy steel frame. Vertical displacements of the cage are transduced by an accelerometer, interfaced with a Macintosh II computer (Apple Computers, Cupertino, CA). Cage movement resulted in displacement of an accelerometer in which the resultant voltage was proportional to the velocity of cage displacement. Startle amplitude was defined as the peak accelerometer voltage that occurred during the first $200 \mathrm{~ms}$ after onset of the startle stimulus.

\section{Startle stimulus}

A $50 \mathrm{~ms}$ (rise-decay, $5 \mathrm{~ms}$ ) burst of white noise $(90,95$, or $100 \mathrm{db}$ ) was delivered through a high-frequency speaker $2 \mathrm{~cm}$ from the front of the cage. Background white noise [ $55 \mathrm{db}$ (sound pressure level)] was provided throughout the experiment.

\section{Group versus isolation effects on acoustic startle}

On each of $2 \mathrm{~d}, 36$ group-housed rats were placed in the startle chambers and, 5 min later, were presented with 30 startle-eliciting white-noise bursts (10 each at 90, 95, and $105 \mathrm{db}$, presented in a balanced irregular order), at an interstimulus interval of $30 \mathrm{~s}$. The first day of testing served to acclimate the animals to the startle stimulus and test chambers. The second day of testing served as the pretest. The rats were then divided into two groups, each having equivalent pretest mean startle amplitudes across the 30 startle stimuli. One group of rats $(n=16)$ was group housed (in groups of four), whereas rats in the other group $(n=20)$ were individually housed for 3 weeks. Individually housed rats had no access to other rats, but they could still view, smell, and hear other rats in the vivarium. One animal was dropped before matching because of unusually high pretest startle amplitude ( $\sim 3.5$ SDs above the mean for the group). Both groups of animals were then tested again on acoustic startle using the same protocol as in matching, although testing was conducted on only $1 \mathrm{~d}$ (postisolation startle). The difference between preisolation and postisolation mean startle amplitude across the 30 test stimuli (for animals in the isolation group) was calculated for each animal and termed IPS.

The 20 animals in the isolation group were subsequently used for the individual differences in receptor binding study. After testing, these animals were returned to their cages and housed individually again for 2 weeks. We waited for 2 weeks to increase the likelihood that individual variation in receptor levels were not created by the startle procedure itself. They were then killed, and their brains were rapidly removed, frozen on dry ice, and stored at $-80^{\circ} \mathrm{C}$ until tissue processing.

\section{Autoradiographic receptor binding and image analysis}

Binding. Brains were cryostat sectioned at $20 \mu \mathrm{m}$ and thaw mounted onto Superfrost microscope slides. Six sets of sections were cut and mounted onto adjacent slides, resulting in an $\sim 120 \mu \mathrm{m}$ distance between each section on a slide. Four of the six series of sections were used for V1aR, OTR, CRF1, and CRF2 autoradiographic binding (Wang and Young, 1997; Young et al., 1997; Sanchez et al., 1999). Slides were thawed and air dried for $30 \mathrm{~min}$ and then fixed for $2 \mathrm{~min}$ in $0.1 \%$ paraformaldehyde. Slides were rinsed twice in $50 \mathrm{~mm}$ Tris base, $\mathrm{pH}$ 7.4, solution for $10 \mathrm{~min}$ each and then incubated in tracer for $1 \mathrm{~h}$. The tracer buffer for each binding consisted of $50 \mathrm{~mm}$ Tris base, $10 \mathrm{~mm} \mathrm{MgCl}, 0.1 \%$ bovine serum albumin, and one of the following tracers.

V1aR binding. For V1aR binding, 50 pM ${ }^{125} \mathrm{I}$-vasopressin (linear), a $\mathrm{V} 1 \mathrm{aR}$ antagonist (NEX3100; PerkinElmer, Wellesley, MA), was used. The $K_{\mathrm{d}}$ of this ligand for the rat VlaR has been reported as 8 pM with a 400-to 1000-fold lower affinity for the $\mathrm{V} 1 \mathrm{aB}, \mathrm{V} 2$, and OTR receptor (Barberis et al., 1995). Previous autoradiographic studies using 50 pм of this ligand demonstrated no displacement of labeling by selective unlabeled OTR receptor ligands (Wang et al., 1997).

OTR binding. For OTR binding, $50 \mathrm{pm}{ }^{125} \mathrm{I}$-ornithine vasotocin analog (NEX2540; PerkinElmer) was used. The $K_{\mathrm{d}}$ for this ligand is $\sim 30 \mathrm{pM}$ and has a 300 -fold greater affinity for the OTR receptor than for the V1aR and V2 receptors (Barberis and Tribollet, 1996). The concentration has been used previously to quantify OTR in the rat brain (Barberis and Tribollet, 1996).

CRF1 and CRF2 binding. Because no selective ${ }^{125} \mathrm{I}$-labeled CRF2 ligands exist to our knowledge, we performed total CRF1 and CRF2 binding using $200 \mathrm{pm}{ }^{125}$ I-sauvagine (NEX3060; PerkinElmer) and then CRF2 binding using 200 pM ${ }^{25} \mathrm{I}$-sauvagine and an excess of unlabeled CP154526, a selective CRF1 antagonist (Schulz et al., 1996) to selectively compete out CRF1 receptor sites. The $K_{\mathrm{d}}$ of ${ }^{25} \mathrm{I}$-sauvagine for CRF1 is 200-400 pM and for CRF2 is 100-300 pM (Grigoriadis et al., 1996; Primus et al., 1997). Using the total and CRF2 binding values, CRF1 binding was calculated as total ${ }^{125} \mathrm{I}$-sauvagine binding minus CRF2 binding (Sanchez et al., 1999; Lim et al., 2005). CP154526 was kindly provided by Dr. Mike Owens (Emory University, Atlanta, GA).

Slides were rinsed four times with $50 \mathrm{~mm}$ Tris base plus $10 \mathrm{~mm} \mathrm{MgCl}$, $\mathrm{pH} 7.4$, at $5 \mathrm{~min}$ each and then once more for $30 \mathrm{~min}$ with stirring. Slides were then rinsed in deionized $\mathrm{H}_{2} \mathrm{O}$, blow dried with cool air, and apposed to Kodak MR film (Eastman Kodak, Rochester, NY) and stored in Kodak autoradiographic cassettes for $85 \mathrm{~h}$ for each ligand. ${ }^{125} \mathrm{I}$ standards were included with each film.

\section{Image analysis}

Binding was quantified using AIS 6.0 Image Analysis software (Imaging Research, St. Catharine's, Ontario, Canada). Films were placed on a direct current-powered light box, and images were captured through a Dage-MTI (Michigan City, IN) CCD72 camera and digitized. The image was corrected for optical distortions (flat-field correction). Relative optical density measurements, taken bilaterally across two to three sections and averaged for each brain region, were automatically converted to microcuries per gram values based on a known set of ${ }^{125} \mathrm{I}$ standards (Amersham Biosciences, Arlington Heights, IL) included with each film. V1aR, OTR, CRF1, and CRF2 binding across different subregions of the lateral septum, bed nucleus of the stria terminalis, accumbens, amygdala, and cingulate cortex (a total of 39 binding values) were quantified. The regions of interest (ROIs) are presented in Figure 2, and abbreviations are presented in Table 1.

V1aR binding was quantified in the following: dorsal (LSd), intermediate (LSi), and ventral lateral septum (LSv); lateral (BNSTl), medial posterointermed (BNSTmp), and medial posterolateral (BNSTmpl) region of the bed nucleus of the stria terminalis (BNST); and the basolateral (BlA), central (CeA), and medial amygdala (MeA).

OTR binding was quantified in the AccSh, LSi, BNSTl, BNSTmp, BNSTmpl, BlA, CeA, and MeA. 


\section{Table 1. Abbreviations}

\begin{tabular}{ll}
\hline LSd & Lateral septum, dorsal \\
LSi & Lateral septum, intermediate \\
LSv & Lateral septum, ventral \\
BNSTI & Bed nucleus of the stria terminalis, lateral \\
BNSTmp & Bed nucleus of the stria terminalis, medial, posterointermed \\
BNSTmpl & Bed nucleus of the stria terminalis, medial, posterolateral \\
CeA & Central nucleus, amygdala \\
BIA & Basolateral nucleus, amygdala \\
MeA & Medial nucleus, amygdala \\
CgA & Cingulate cortex, anterior \\
Cg & Cingulate cortex \\
AccSh & Nucleus accumbens, shell \\
\hline
\end{tabular}

CRF1 and CRF2 binding was quantified in the AccSh, anterior cingulate cortex (CgA), Cg, LSd, LSi, LSv, BNSTl, BNSTmp, BNSTmpl, BlA, $\mathrm{CeA}$, and MeA. The AccSh is not shown for CRF2 because binding approximated background levels.

\section{Statistics}

Binding for the 20 animals had to be performed in two different batches, with some subjects in the first and others in the second. To reduce the effects of interbatch variability, we residualized all binding values against a whole-brain value (i.e., we statistically removed whole brain and therefore batch effects from the data). The whole-brain binding value was obtained by taking an average binding measurement for each brain section across all brain sections and then taking an average of these values. Regression was used to obtain residual binding values (Nair et al., 2001).

Our aim was to use multiple regression analysis to assess whether, among the 39 sampled binding sites, there was a particular combination of sites in which receptor binding significantly predicted IPS. Because entering all 39 binding sites into a multiple regression analysis is invalid (Stevens, 1996), we used a multivariate extension of correlational analysis known as PLS (McIntosh et al., 1996, 1999; Nair et al., 2001; Nair and Gonzalez-Lima, 2003; McIntosh and Lobaugh, 2004) to identify candidate regions. Multiple regression analysis was then used to assess whether the candidate regions were significantly associated with behavior.

\section{PLS}

PLS, or "behavioral" PLS as performed here, is an analysis that identifies systems of brain regions demonstrating maximal covariation with a behavior measure. Rather than analyzing individual correlations between each brain region and behavior, one can use PLS to evaluate the set of correlations as a whole. It identifies from the set of brain/behavior correlations which ones account for most of the covariation in a single, omnibus step. By considering the brain/behavior correlations simultaneously, PLS preserves the statistical power lost when performing multiple correlational tests.

The output of the behavioral PLS is a set of numerical weights (saliences) similar to correlation coefficients that describe the covariation between each brain region and the behavioral measure. Regions with higher weights demonstrate stronger covariation with behavior. The reliability of the weights is confirmed using a bootstrapping method in which the sets of subjects are randomly sampled with replacement and the PLS is recalculated 1000 times. The SE for each salience is derived from the set of bootstrapped PLS analyses. The original salience divided by the SE, which approximates a $z$ score for normal bootstrapped distribution, is then taken to be the measure of reliability (McIntosh and Lobaugh, 2004). Here we attempted to identify those regions that demonstrated the strongest, most reliable associations with behavior and therefore used a criterion of 3 as the ratio needed to serve as a candidate region for the multiple regression analysis. For details on the computation of PLS see, McIntosh et al. (1996) and McIntosh and Lobaugh (2004).

Two separate PLS analyses were conducted: one examining the covariation between IPS and binding, and the other examining covariation between pre-isolation baseline startle and binding. If a region was correlated with both IPS and pre-isolation baselines (that is, binding was not uniquely associated with IPS and perhaps more related to baseline startle), it was not included in the subsequent regression analysis.

\section{Multiple regression}

After PLS, multiple regression analysis was used to assess the combined contribution the identified regions made to behavior. Multiple regression analysis as applied here results in an equation of the form $y=b_{1} \times$ $x_{1}+\ldots b_{n} \times x_{n}+c$, where $y$ is IPS, and $x$ are the binding values. The Pearson's $r$ correlation between observed IPS and predicted IPS (i.e., the linear combination of binding values) is the multiple $R$ value. A significant multiple $R$ value means the correlation between predicted and actual values is significant. The percentage of variance explained by the independent variables is indicated by $R^{2}$. Simple regression between IPS and each candidate region was performed separately as a way of evaluating the difference in percentage of variance accounted for by the linear combination of regions versus each region separately.

Multiple regression returns a corresponding $t$ value with $p$ level as an indication of the unique contribution to $y$ by each independent variable (partialling out correlations among independent variables). We evaluated these values in conjunction with a correlational analysis of the ROIs to assess the degree to which multicollinearity, or intercorrelations among the binding values, affected the regression analysis. Furthermore, we used this analysis to ascertain whether the binding in the candidate regions were related to each other. We did this to rule out the possibility that multiple regions are correlated with behavior simply because they are highly correlated among themselves.

\section{Predictive validity analysis}

To validate the regression analysis, we tested 12 additional animals on startle before and after 3 weeks of isolation, processed their brains, and measured binding in the same regions identified by the original PLS. For these animals, we simply subtracted a background value measured in the dorsal striatum to correct for background (ensuring that the relationships we obtained in the first analysis were not an artifact of the residualization). The values were then entered into the original equation (i.e., they were multiplied through the weights of the original equation) to obtain predicted behavioral values, and the predicted versus observed correlation was evaluated accordingly (Horwitz et al., 1992): the Pearson's $r$ value was converted to Fisher's $z$ value (Fisher's $r-z$ transformation) using the formula: $z^{\prime}=0.5\left[\log _{e}((1+r) /(1-r))\right]$.

Whether the correlation was significantly different from 0 was tested using the formula $Z=z^{\prime} / \alpha$, where $\alpha$ is the bootstrapped estimate of the SD of the $z^{\prime}$, and $Z$ approximates a $z$ score. A $Z$ value $>1.96$ (approximating the $z$ score value at the 97.5 th percentile for a normal distribution) was considered to be significant.

We also evaluated the likelihood of obtaining the same relationship between predicted and observed behavioral scores if we (1) correlated IPS with permuted sets of ROI values or (2) if we generated random numbers for the ROI values and entered those into the equation. For both procedures, we performed 100 permutations or generated 100 sets of random numbers, computed the predicted scores, and then correlated them with the observed behavior. Using the same Fisher's $z$ transformation, we evaluated the number of times we obtained a $Z$ value greater than or equal to the original.

PLS, permutation, and random number tests were performed in Matlab (MathWorks, Natick, MA). Regression analyses were performed in SPSS (SPSS, Chicago, IL).

\section{Changes in binding attributable to isolation}

To test whether there were changes in binding density attributable to the isolation itself, we pretested a new set of 24 group-housed male rats for baseline startle, isolated half of them for 3 weeks, and retested all animals. Their brains were removed, and binding for OTR, V1aR, and CRF1 was performed. V1aR binding was quantified in the BNSTl, OTR in the LSi, and CRF1/CRF2 in the AccSh. Because the previous analyses showed no CRF2 binding in the AccSh (i.e., CRF2 values were no different from background), we simply used the total CRF1/CRF2 values for the AccSh measurement. For each region, differences in binding between grouped 
versus isolated animals were assessed using a $t$ test. Because it is still possible that isolation may differentially affect individual animals such that receptors are altered in some animals but not others, we used an $F$ test for the equality of two variances (Rosner, 2006) to statistically evaluate variance in binding between grouped and isolated animals.

\section{Bilateral CRF infusions into the AccSh: grouped versus} isolated effects

The combined PLS/multiple regression analysis revealed that CRF1 receptors in the AccSh were significantly correlated with IPS in the positive direction. We therefore tested whether CRF infusion into the AccSh could potentiate startle under grouped or isolated housing.

One week after arrival at our vivarium, 12 male rats were anesthetized with a mixture of ketamine $(75 \mathrm{mg} / \mathrm{kg}) /$ domitor $(0.5 \mathrm{mg} / \mathrm{kg}$ ) (Pfizer, Groton, CT) and mounted in a David Kopf Instruments (Tujunga, CA) stereotax. Dual guide cannulas with a distance of $1.5 \mathrm{~mm}$ between cannulas (26 gauge, model C235G; Plastics One, Roanoke, VA) were implanted into the shell of the accumbens using the following coordinates with respect to bregma: anteroposterior, 1.70; mediolateral, -0.8 ); dorsoventral, -6.4 . For the mediolateral coordinate, the right cannula was placed on bregma and then moved to the right $0.8 \mathrm{~mm}$. After surgery, animals were administered the anesthetic reversing agent Antisedan $(0.5 \mathrm{mg} / \mathrm{kg})$ and allowed to recover for 1 week. Three of the 12 animals were found to have blocked cannulas after surgery, and two of the remaining nine animals had misplaced cannulas on performing histology after the infusion study. These animals were excluded from the study.

The day before the testing protocol began, we acclimated animals to the testing procedures by placing them in the startle chambers and giving them $3095-\mathrm{db}$ startle stimuli. The next day (day 1 of testing), subjects were placed in the startle chambers and given $2 \mathrm{~min}$ of white noise, followed by 117 startle stimuli every $30 \mathrm{~s}$ (39 each of 90 , 95, or $100 \mathrm{~dB}$ noise bursts presented in a pseudorandom order). This startle testing procedure lasted exactly $60 \mathrm{~min}$.

On day 2, half of the animals received $500 \mathrm{nl}$ of vehicle (artificial CSF), whereas the other half received CRF into the AccSh bilaterally (200 ng/ $500 \mathrm{nl}$ per side). Animals were then tested immediately on the $1 \mathrm{~h}$ baseline protocol above. On day 3, animals were "crossed-over" such that subjects received the opposite treatment. Subjects were then tested again on the baseline startle paradigm. Immediately after testing on day 3 , all animals were housed individually and remained isolated for $2 \mathrm{~d}$ (days 4 and 5).

On days 6 and 7, the crossover design described for days 2 and 3 was repeated (see Fig. $6 B$ ).

Statistics. Startle measurements for each $15 \mathrm{~min}$ period were averaged yielding four startle measurement time points for each animal $(0-15$, 15-30, 30-45, and 45-60). We then applied a two-way repeatedmeasures ANOVA on each time point in which treatment (CRF or vehicle) and housing (grouped or isolated) served as the between-groups factors.

Histological verification of cannula placements. After behavioral testing, animals were deeply anesthetized with $20 \%$ chloral hydrate, perfused with PBS, and fixed with $4 \%$ paraformaldehyde. Their brains were removed and placed in a $20 \%$ sucrose $/ 4 \%$ paraformaldehyde solution overnight. Brain were sectioned the next day at a $50 \mu \mathrm{m}$ thickness, mounted on slides, and stained for cresyl violet. Sections were cleared for 2 min in $100 \%$ and $95 \% \mathrm{ETOH}$, dipped in cresyl violet solution for 10 min, cleared in 70, 95, and 100\% ETOH, washed in xylene for $10 \mathrm{~min}$, and coverslipped.

\section{Results}

After 3 weeks of isolation, rats demonstrated a significant potentiation of startle relative to group-housed animals (Fig. 1A). However, there was substantial individual variation in the degree to which animals demonstrated IPS (Fig. $1 B$ ).

Animals in the isolated group were killed, and their brains were processed for OTR, V1aR, CRF1, and CRF2 binding. The sampled binding sites are presented in Figure 2.
A

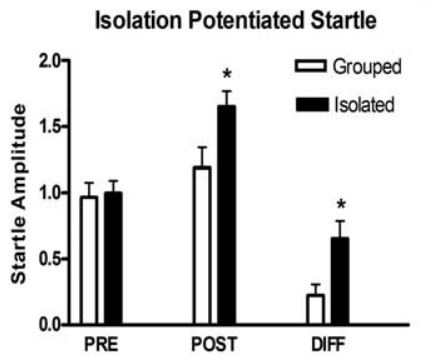

Figure 1. $\quad$ A, Animals were tested before (PRE) and after (POST) 3 weeks of grouped versus isolated housing. Animals in the isolated group demonstrated a greater difference (DIFF) in startle. $\boldsymbol{B}$, Individual variation in IPS among animals from the isolated group in $\boldsymbol{A}$.

\section{PLS analysis}

Behavioral PLS revealed that, across the sampled regions, V1aR, OTR, and CRF2 binding were generally negatively correlated with IPS, whereas CRF1 binding was generally positively correlated with IPS (Fig. 3). The bars in Figure 3 indicate the degree of covariation with behavior, and the direction indicates sign. Behavioral PLS identified four areas in which V1aR, OTR, and CRF1 binding were predictive of IPS. V1aR binding in the BNSTl and LSd, OTR in the LSi, and CRF1 in the AccSh were revealed to have the highest and most reliable covariance relationship with IPS. V1aR binding in the BNSTl and LSd and OTR binding in the LSi demonstrated negative saliences with IPS, indicating that animals with greater IPS showed less binding in these regions. The opposite occurred for CRF1 in the AccSh: higher IPS scores were associated with more CRF1 binding in the AccSh. Behavioral PLS using the pre-isolation baseline revealed that V1aR binding in the LSd was significantly associated with baseline startle (data not shown). Therefore, for the subsequent multiple regression analysis, only the binding values for the BNSTl, LSi, and AccSh were used.

\section{Multiple regression}

A significant multiple regression analysis $(F=3.51 ; p=0.04)$ was obtained, with an $R$ value of 0.63 and an $R^{2}$ value of 0.40 , indicating that $\sim 40 \%$ of the variance in IPS was accounted for by the three regions (Table 2). Predicted versus obtained values are illustrated in Figure 4. Simple regression analysis revealed that V1a binding in the BNSTl (Fig. 4A) and CRF1 binding in the AccSh (Fig. 4C) demonstrated a multiple $R$ close to significance, whereas OTR binding in the LSi (Fig. $4 B$ ) was significant (Table 2). In each case, the $R$ value approximated 0.45 (an $R^{2}$ value approximating $20 \%$ of the IPS variance), which is $20 \%$ lower than the variance accounted for when all were included together in the multiple regression analysis. IPS and predicted values were $z$ transformed to render the data unitless for presentation purposes.

\section{Intercorrelations among identified variables}

Standardized $\beta$ weights and corresponding $t$ values and $p$ levels for each region are indicated in Table 3 . None of the $\beta$ weights associated with the entered variables were significant, indicating that, although the regions as a group contributed to an overall significant multiple regression, the individual contribution of each was not significant. This usually occurs when there are high intercorrelations (multicollinearity) among the entered variables (Stevens, 1996). Therefore, we examined the intercorrelations among the ROIs. 
V1a

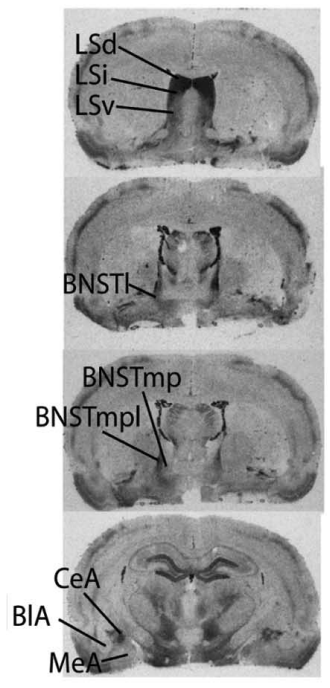

OTR

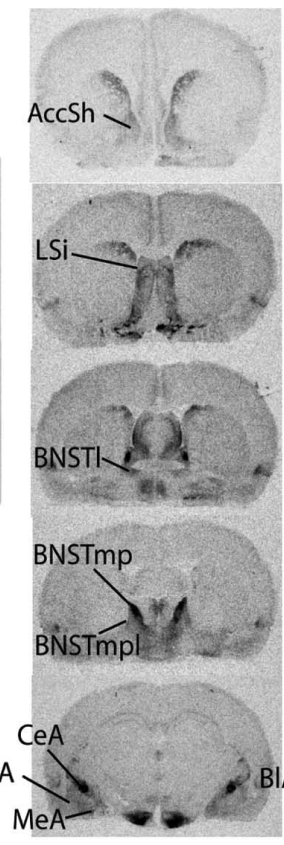

CRF1/2

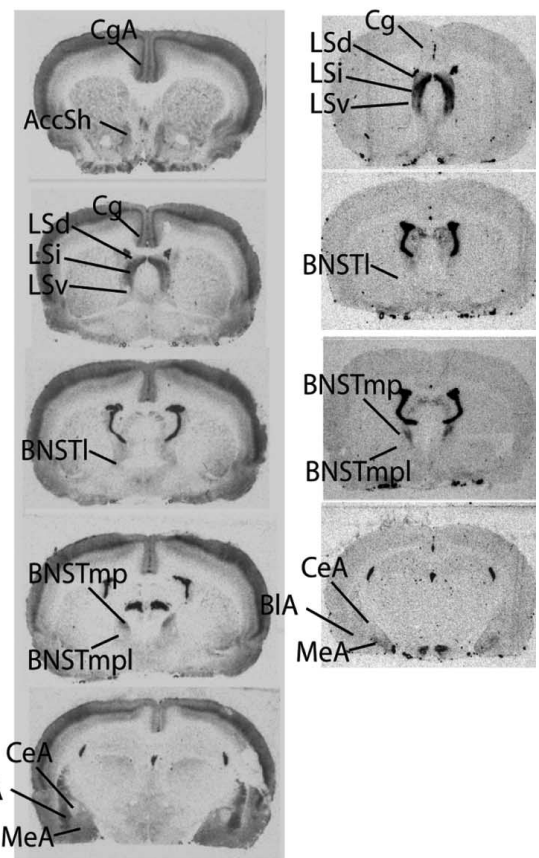

Figure 2. Sampled receptor binding sites for V1aR, OTR, CRF1, and CRF2 are as shown. Coordinates are as follows: AccSh and $\mathrm{CgA}, 1.00 \mathrm{~mm}$ from bregma; $\mathrm{LSd}$, LSi, and LSv, $0.7 \mathrm{~mm}$ from bregma; BNSTI, $-0.4 \mathrm{~mm}$ from bregma; BNSTmp and BNSTmpl, $-0.8 \mathrm{~mm}$ from bregma; BIA, CeA, and MeA, $-2.8 \mathrm{~mm}$ from bregma.

Pearson $r$ values between the identified regions are presented in Table 4. There were no significant correlations. However, both OTR binding in the LSi and CRF1 binding in the AccSh were moderately correlated with V1aR binding in the BNSTl $(r=0.24$ and -0.31 , respectively) (Table 4 ). We therefore recalculated the multiple regression leaving the BNSTl out and obtained $t$ values that were close to significance for both LSi and ACC (0.06 and 0.08 respectively) (Table 5 ).

Therefore, this analysis reveals that all three regions make independent contributions to IPS, although the combination of the three accounts for more of the variation in IPS. OTR binding in the LS and CRF1 binding in the Acc appear to be weakly correlated with $\mathrm{VlaR}$ binding in the BNSTl.

\section{Increasing the number of independent variables}

To test whether the significance of the regression model occurs simply because of increasing the number of variables, we decreased the reliability criteria for the PLS so that a greater number of regions were entered into the multiple regression analysis. By decreasing the PLS requirement to 2 , an additional six regions in which binding covaried with IPS (V1aR binding in the LSv and LSi, OTR binding in the AccSh, BNSTl, and BlA, and CRF1 binding in the BLA) were identified and entered into the multiple regression equation. The addition of these extra regions resulted in a nonsignificant multiple regression.

\section{Test of predictive value}

To test the predictive validity of the regression analysis, we took the binding values for V1aR in the BNSTl, OTR in the LSi, and CRF1 in the AccSh from a new set of animals and obtained a linear combination of these values based on the equation obtained from the original set of animals. These scores were then correlated with the animals' actual IPS scores. The correlation between actual and predicted behavioral scores was $0.68(p<0.05)$, indicating that the original equation significantly predicted a new set of animal's IPS scores. Predicted versus obtained scores are illustrated in Figure 5. In both the permutation and random number analyses, the likelihood of obtaining a $z$ value the same or above was $<0.001$ in both cases. The average $r$ value for the permuted or random number analysis approximated 0 .

\section{Binding differences between grouped versus isolated subjects}

To test the hypothesis that isolation itself may change receptor levels, we compared V1aR, OTR, and CRF1 binding in the BNSTl, LSi, and AccSh, respectively, between a new set of group-housed subjects $(n=$ 12) and subjects that had been isolated for 3 weeks $(n=11)$. There were no differences in binding for CRF1 in the AccSh $(11.1 \pm 1.0 \mathrm{nCi} / \mathrm{g}$ for grouped vs $9.9 \pm 1.2$ $\mathrm{nCi} / \mathrm{g}$ for isolated), V1aR in the BNSTl $(36.8 \pm 5.0 \mathrm{nCi} / \mathrm{g}$ for grouped vs $46.7 \pm$ $5.0 \mathrm{nCi} / \mathrm{g}$ for isolated), or OTR in the LSi $(24.32 \pm 4.3 \mathrm{nCi} / \mathrm{g}$ for grouped vs $23.7 \pm$ $4.5 \mathrm{nCi} / \mathrm{g}$ for isolated). An unpaired $t$ test was used for all comparisons. The equality of variance test also demonstrated no differences in variability between isolated and grouped animals for all three peptides $\left(\mathrm{CRF} 1, F_{(11,10)}=1.28, p=0.34 ; \mathrm{V} 1 \mathrm{aR}\right.$, $F_{(11,10)}=0.67, p=0.74$; OTR, $\left.F_{(11,10)}=0.94, p=0.54\right)$.

\section{CRF infusion into the AccSh}

We applied two-way repeated-measures ANOVA at each time point (0-15, 15-30, 30-45, and 45-60) in which treatment (CRF or vehicle) and housing (grouped or isolated) served as the repeated-measures, between-groups factors. ANOVA revealed a significant treatment $\times$ housing interaction $\left(F_{(1,8)}=17.77 ; p<\right.$ $0.01)$ at the 45-60 time interval. The overall ANOVA was followed up by post hoc $t$ tests that revealed CRF infusion caused a significantly greater increase in startle when animals were isolated versus group housed $\left(t_{(6)}=3.81 ; p<0.05\right)$. CRF infusion during isolation also caused a significant increase in startle relative to vehicle treatment $\left(t_{(6)}=2.71 ; p<0.05\right)$. No significant differences were found between CRF and vehicle infusion when animals were group housed, nor was there a difference in animals when isolated and given vehicle treatment.

To summarize the AccSh infusion data, subjects demonstrated no potentiation of startle across the hour of testing when they were group housed or treated with vehicle during isolation. Across the hour of testing, there was a gradual decreasing trend observed under these conditions. Alternatively, a marked increase in startle was observed across the hour of testing when animals were isolated and infused with CRF that reached its peak in the last $15 \mathrm{~min}$ of testing. Therefore, $200 \mathrm{ng}$ of CRF infused bilaterally into the AccSh only had an effect if animals were in the isolated condition (Fig. 6).

\section{Discussion}

Individual housing has long been known to increase anxiety-like behavior in the open-field test (Stern et al., 1960) and adrenal 
hyper-responsivity (Hatch et al., 1963) in rats. Furthermore, isolation-induced reductions in time spent on the open arm in the elevated plus maze are reversed by the anxiolytic compound chlordiazepoxide (Haller and Halasz, 1999). Because other anxiogenic manipulations such as intracerebroventricular CRF infusions (Swerdlow et al., 1986; Liang et al., 1992; Lee and Davis, 1997) or a bright light (Walker and Davis, 1997) increase startle, we presume that the IPS effect observed here also reflects increased anxiety, albeit anxiety arising from the absence of social contact. The absence of both mean differences and differences in variability in peptide receptor expression patterns between grouped and isolated animals suggests that the correlation between IPS and receptor binding reflects a trait effect, i.e., it is not a transient effect of the isolation.

The PLS analysis found three regions, the BNSTl, LSi, and AccSh, each associated with three different peptide systems, V1aR, OTR, and CRF1, respectively, showing covariances with IPS. Specifically, those animals showing greater IPS had reduced V1aR in the BNSTl, reduced OTR in the LSi, and greater CRF1 in the AccSh. Multiple regression analysis combined with the predictive validity test extended the PLS results by demonstrating that the linear combination of these regions/receptors significantly predicted IPS and accounted for more of the variation than when each region was considered individually. Our results therefore suggest that a complex interaction of multiple neuropeptide systems across several brain regions can better explain a behavioral effect such as IPS.

Discovery-based approaches have recently been applied to gene arrays (Pomeroy et al., 2002; Whitfield et al., 2003), and neuroimaging studies have long applied them toward identifying patterns of functional activation associated with behavior (Petersson et al., 1999; Sommer and Wichert, 2003). This is the first time to our knowledge that they have been applied to discover brain neuropeptide patterns that predict vulnerability to a stressor such as isolation. The utility of these approaches is that they can generate novel hypotheses, ones not readily predicted by previous data. Here, we found a strong covariation between CRF1 receptors in the AccSh and IPS, a relationship we would not have predicted given the paucity of evidence linking CRF, AccSh, and social isolationinduced anxiety. The positive correlation between CRF1 receptors in the AccSh and IPS predicts that CRF infused into the region will potentiate startle. Interestingly, we found this to be the case, but only after animals were isolated for $2 \mathrm{~d}$. These data suggest that other isolation-induced alterations in brain physiology may interact with CRF in the AccSh to give rise to the change in startle.

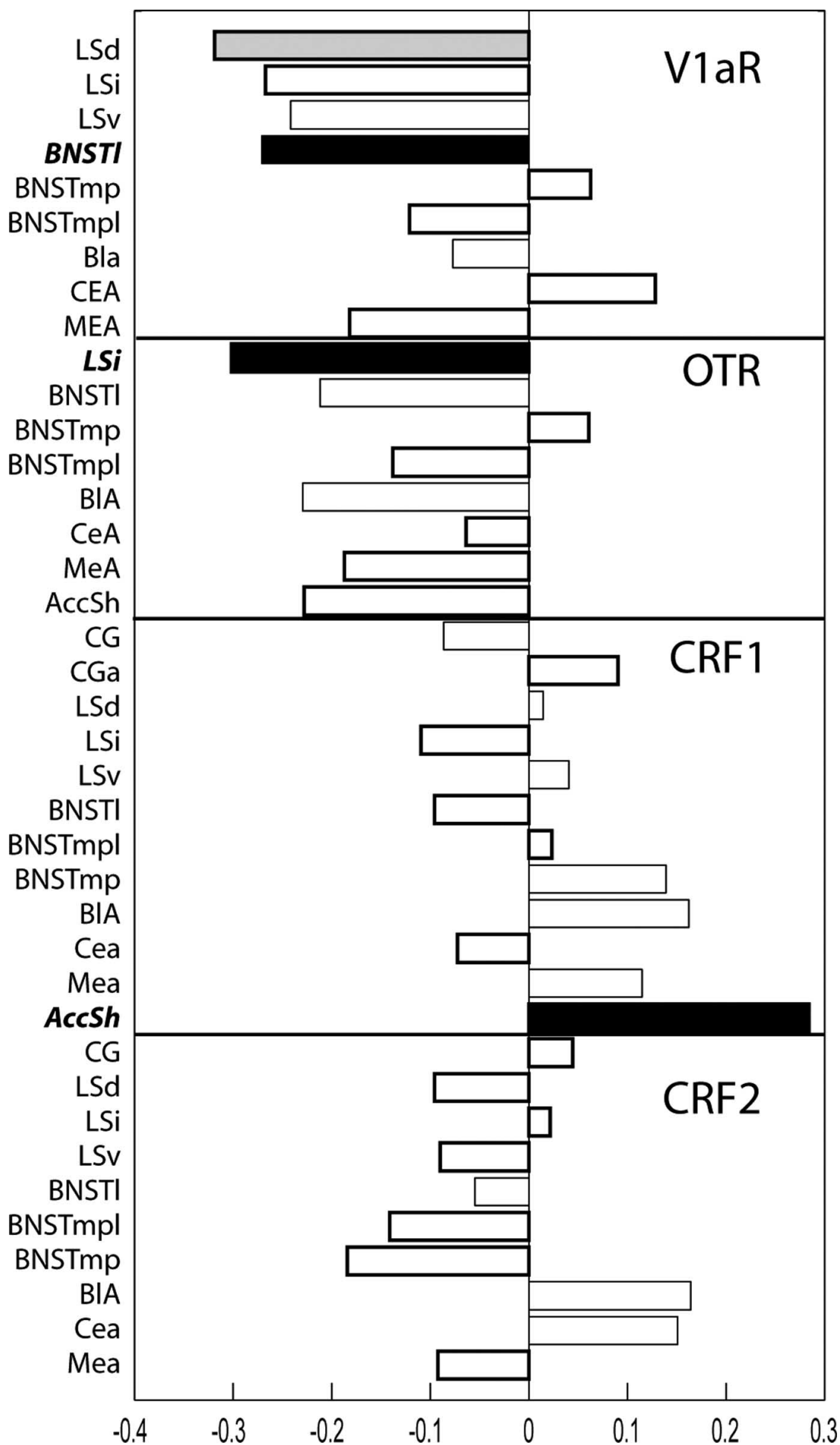

Figure 3. PLS analysis. PLS analysis revealed that V1a binding in the BNSTI, OTR in the LSI, and CRF1 in the AccSh demonstrated the strongest, most reliable covariation with IPS. These regions/receptors are indicated by the black bars and were subsequently used for the multiple regression analysis. V1a binding in the LSd (shown in gray) showed strong covariation with both IPS and preisolation baseline and was not used for the regression analysis. The bars indicate the magnitude and direction of the saliences or weights associated with the covariation of each brain regions with IPS. A negative salience indicates a negative correlation between IPS and binding and a positive salience indicates a positive correlation. The filled bars indicate significant saliences based on the bootstrapping reliability measure.

Therefore, the complex interaction of peptides suggested by the PLS and regression analyses is further supported by the infusion data. Although there could be several other peptide and/or neurotransmitter systems interacting with CRF, we suspect that oxy- 
Table 2. Multiple and simple regression results

\begin{tabular}{lllll}
\hline & $R$ & $R^{2}$ & $F$ & $p$ \\
\hline Combined & 0.630 & 0.397 & 3.51 & 0.040 \\
V1a, BNSTI & 0.416 & 0.173 & 3.776 & 0.068 \\
OTR, LSi & 0.464 & 0.215 & 4.927 & 0.040 \\
CRF1, AccSh & 0.437 & 0.191 & 4.248 & 0.054 \\
\hline
\end{tabular}

Multiple regression for the three receptors/regions identified by the PLS analysis combined or simple regression for each individual receptor/region was performed. Multiple or simple $R$ and $R^{2}$ (percentage of variance in IPS accounted for), $F$ value associated with $R$, and level of significance $(p)$ are indicated. Although simple regression shows that each region by itself accounts for close to $20 \%$ of the variation in IPS, $40 \%$ of the variation was accounted for by the combined analysis.
A.

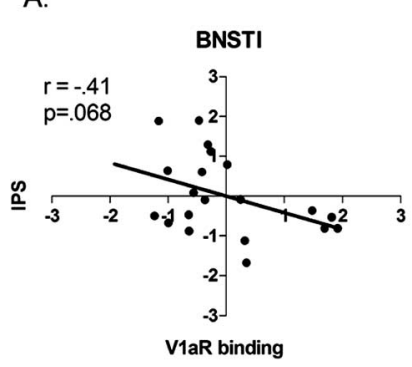

B.

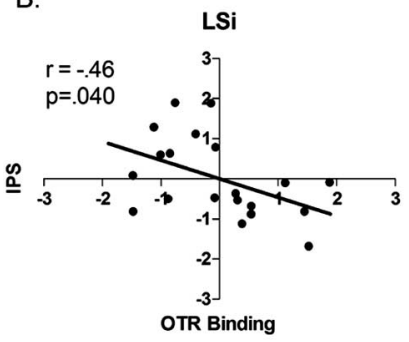

C.

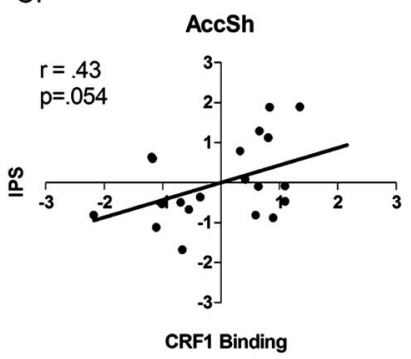

D.

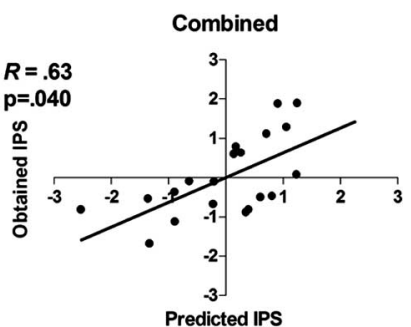

Figure 4. Simple and multiple regression results. Simple regression revealed that V1a binding in the BNSTI $(\boldsymbol{A})$ and OTR binding in the $L \mathrm{Si}(\boldsymbol{B})$ had regression slopes $(r)$ of -0.41 and -0.46 , respectively. CRF1 binding in the shell of the accumbens had an $r$ of $0.43(C)$. These associations were weaker than the multiple-regression-derived linear combination of these binding values (Predicted IPS) (D).

Table 3. Test of $\boldsymbol{\beta}$ weights

\begin{tabular}{lrrl}
\hline & SBW & $t$ & $p$ \\
\hline BNST, Vla & -0.234 & -1.123 & 0.278 \\
LSi, OTR & -0.357 & -1.778 & 0.094 \\
AcCSh, CRF1 & 0.307 & 1.495 & 0.154
\end{tabular}

Standardized $\beta$ weights (SBW), their corresponding $t$ value, and significance $(p)$ are indicated. Although a significant multiple regression was found, there was a lack of significance for the individual $\beta$ weights, which may have been attributable to multicollinearity between receptors/regions. This was assessed by the correlational analysis (see Table 4).

tocin and vasopressin may be important candidates because they are shown here to be linked to IPS.

\section{AccSh, BNST, and LS network in IPS}

The AccSh is directly continuous with the central division of the extended amygdala, which includes the BNSTl (de Olmos and Heimer, 1999), and the BNST projects to the lateral septum (Staiger and Nurnberger, 1989). Together, these regions comprise major basal forebrain components in which neuropeptides act to modulate social behavior and anxiety. One possible interpretation of our data is that the PLS/regression approach has identified a circuit mediating anxiety and/or fear, because two of these regions, the BNSTl and LS, are known to regulate these behaviors. For example, potentiation of startle by a bright light is
Table 4. Intercorrelations among ROIs

\begin{tabular}{lcr}
\hline & V1aR, BNSTI & OTR, LSi \\
\hline LSi, 0TR & 0.243 & \\
AcCSh, CRF1 & -0.311 & -0.161 \\
\hline
\end{tabular}

Pearson's $r$ values between binding in the three regions were calculated to test for multicollinearity. There were no significant correlations, although the V1aR in the BNST was weakly correlated with OTR in the LSi and CRF1 in the AccSh.

Table 5. Test of $\boldsymbol{\beta}$ weights leaving out BNSTI

\begin{tabular}{lrrr}
\hline & SBW & \multicolumn{1}{l}{$t$} & $p$ \\
\hline LSi, 0TR & -0.400 & -2.037 & 0.058 \\
AccSh, CRF1 & 0.372 & 1.877 & 0.078 \\
\hline
\end{tabular}

Multiple regression was performed leaving V1a binding in the BNSTI out. Standardized $\beta$ weights (SBW), their corresponding $t$ value, and significance $(p)$ are indicated. Both receptors/regions are close to significance when V1a binding in the BNSTl is removed from the analysis, suggesting that the weak correlations between V1a binding in the BNSTI and the other receptors/regions accounted for the lack of significance of SBW in the full model (see Table 3).

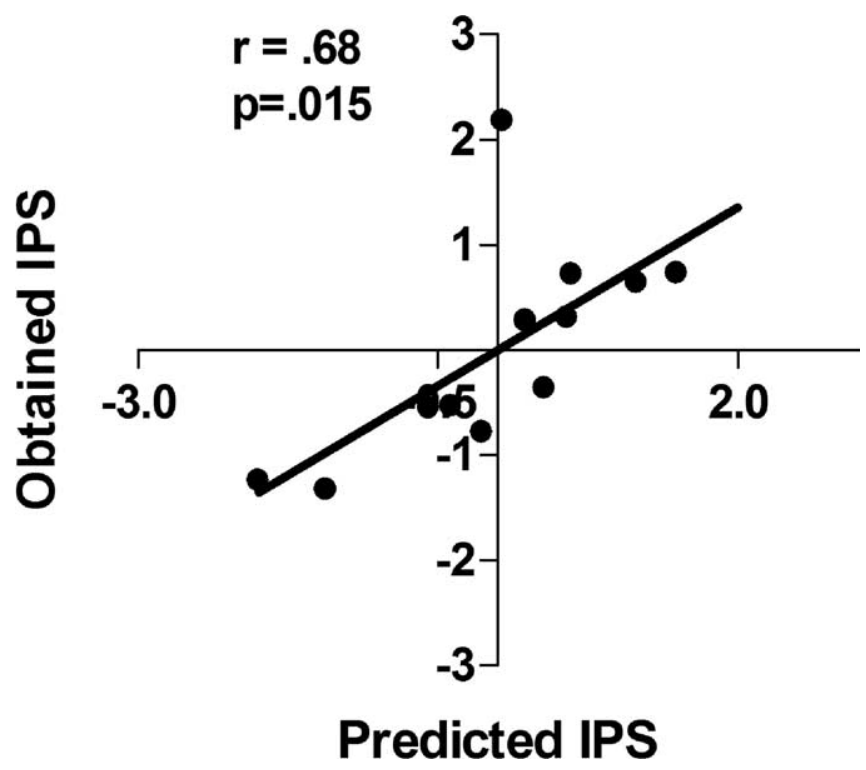

Figure 5. V1a binding in the BNSTI, OTR binding in the LSi, and CRF1 binding from a new set of animals that underwent IPS training were entered into the original multiple regression equation. This linear combination (Predicted IPS) was significantly correlated with IPS.

dependent on the BNSTl (Walker and Davis, 1997), and CRFenhanced startle occurs through CRF1 receptors in the BNSTl (Lee and Davis, 1997). The septum has been implicated in defensive burying, a coping behavior elicited by noxious or anxietyprovoking stimuli (e.g., a shock probe) (De Boer and Koolhaas, 2003). Furthermore, aside from the well known role CRF plays in anxiety and stress (Nemeroff, 1988; Dunn and Berridge, 1990; Liang et al., 1992), oxytocin (Windle et al., 1997; Neumann et al., 2000) and vasopressin (Liebsch et al., 1996; Everts and Koolhaas, 1999; Bielsky et al., 2004; Wigger et al., 2004) are also known to regulate anxiety-like behavior.

Conversely, the particular associations between peptide receptors and brain regions, CRF1/AccSh, OTR/LSi, and V1aR/ $\mathrm{BNSTl}$, suggest that this is not simply an anxiety/fear circuit. Rather, we speculate that the identified network may be linked more specifically to anxiety rooted in changes in a subject's social situation. OXT and AVP are known for regulating social behaviors such as aggression (Winslow et al., 1993; Everts et al., 1997; Giovenardi et al., 1997, 1998; Koolhaas et al., 1998; Young et al., 1998b; Harmon et al., 2002; Lubin et al., 2003; Ragnauth et al., 


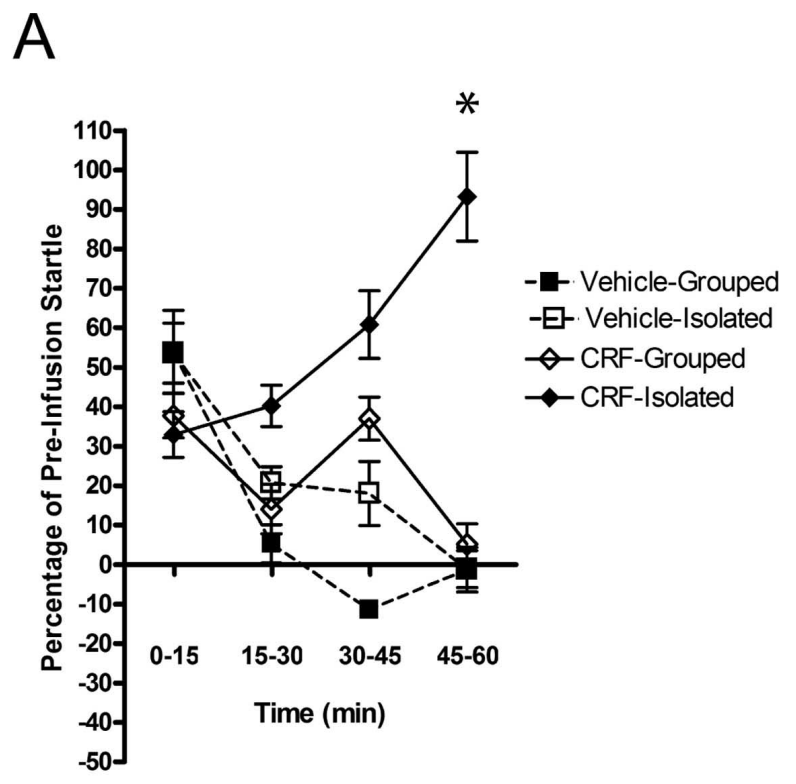

B

\section{DAY1 Baseline}

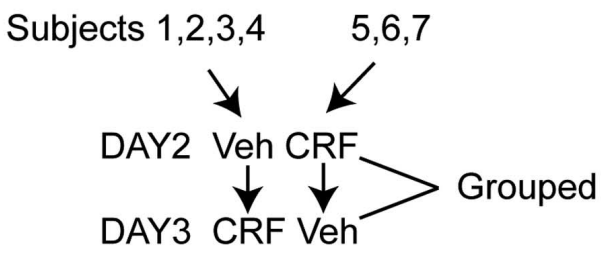

2 days isolation

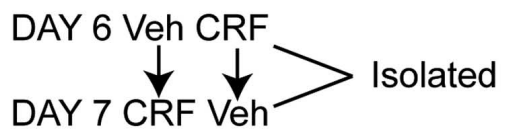

C
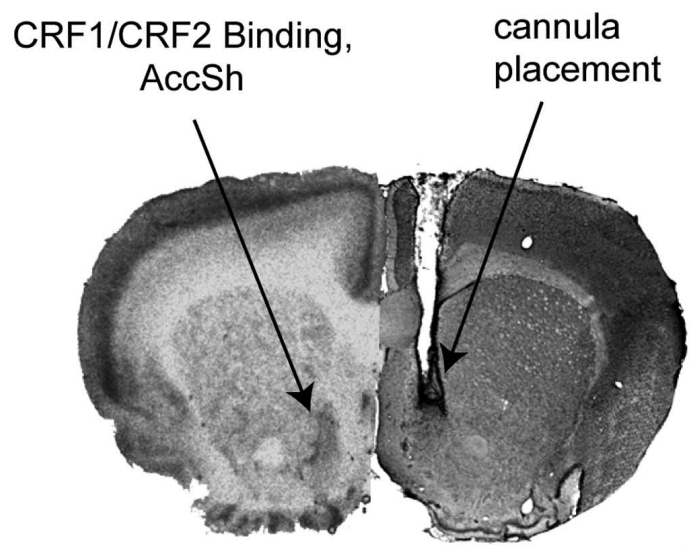

Figure 6. Effects of CRF infusion in the AcCSh. $A$, Bilateral infusions of $200 \mathrm{ng} / 500 \mathrm{nl}$ CRF into the AccSh resulted in a gradual potentiation of startle over the course of $1 \mathrm{~h}$ of baseline startle testing after subjects were isolated for $2 \mathrm{~d}$. The same potentiation of startle was not observed in the same animals when given vehicle or CRF during group housing animals. The asterisk indicates significant group difference at the $45-60$ min time point. $\boldsymbol{B}$, Experimental design. A crossover design was used in which, after baseline testing on day 1, one-half of the subjects received vehicle (Veh), and the other half received CRF and were then tested for startle. On day 2, the same animals were given the alternate treatment and tested again. After $2 \mathrm{~d}$ of isolation, the same crossover design was repeated. C, Cannula placements targeted the CRF receptors in the AccSh.
2005) and affiliation (Insel, 1992; Winslow et al., 1993; Young et al., 1997, 1999; Pitkow et al., 2001; Odendaal and Meintjes, 2003; Kosfeld et al., 2005), and they show remarkable differences in binding distribution across species with distinct social structures (Insel et al., 1991; Insel and Shapiro, 1992; Wang et al., 1996). Recent data also suggest a link between accumbal CRF receptors and social behavior (Lim et al., 2005). The particular patterns we found here in some ways also parallel those that distinguish social versus solitary species [e.g., OTR in the LSi (Insel and Shapiro, 1992)]. Because IPS is a change in startle (which we presume indicates increased anxiety) arising from social isolation, one could imagine that the behavior might be mediated by the integration of systems that mediate both anxiety and social behavior. The particular peptide receptor/brain region combinations support this notion. Future mapping studies of these peptide receptor systems in nonsocial versus socially mediated anxiety paradigms as well as pharmacological manipulations of these brain regions will be needed to explore this idea.

\section{Individual variation in binding}

Our data suggest that, among rats, there may be individual differences in the need for social support and that these differences are related to the distribution patterns of different peptide receptors in the LS/BNST complex and AccSh. The fact that we found no differences between group-housed and isolated animals in their binding levels for the different receptors suggests that these patterns are trait and not state effects. That is, they probably do not arise as a consequence of isolation. An important question then is what establishes these differences. Previous work has demonstrated that both species (Young et al., 1997) and individual differences (Phelps and Young, 2003) in receptor distribution patterns for $\mathrm{V} 1 \mathrm{aR}$ are related to genetic differences in the $5^{\prime}$ regulatory regions for the gene of the receptor (Young et al., 1999; Hammock and Young, 2002; Phelps et al., 2002; Hammock and Young, 2004, 2005). Furthermore, the nature of maternal care can permanently impact the expression levels of peptide receptors in particular regions of the brain of offspring as well (Champagne et al., 2001; Francis et al., 2002). Therefore, it is more than likely a gene $X$ environment interaction that determines the distribution patterns in a given individual and their subsequent behavior.

\section{Summary and conclusions}

Although most neuroscientific research has focused on linking one peptide with a particular behavior (e.g., AVP and affiliation or CRF and anxiety), our data suggest that their integrated activity across several brain regions better explains more complex behavior. Each peptide system may have direct or indirect influences on another, and it may even be suggested that the contribution of one peptide to a behavior such as IPS may depend on the presence of another. Hence, studying the emergent properties of multiple peptide systems in relation to a complex behavior such as IPS may be worthwhile.

Although we presumably studied a form of anxiety, the neuropeptide patterns identified by our approach may be rather specific to anxiety arising from a disruption of an individual's social environment. We speculate that anxiety can be evoked by any number of different of situations, from the potential threat of physical harm to the loss of social support, and that anxiety arising from a particular situation (or general type of situation, e.g., social vs nonsocial) may be associated with a particular neuropeptide receptor pattern. Once these patterns are encoded, presumably through an interaction between genes and 
the prenatal and postnatal environmental conditions, they remain stable into adulthood and determine one's resiliency to particular stressors. Testing of these hypotheses may yield new and valuable information for not only understanding the brain chemistry underlying different forms of anxiety but pave the way for novel therapeutic approaches to anxiety-based mental disorders.

\section{References}

Andrade CS, Guimaraes FS (2003) Anxiolytic-like effect of group housing on stress-induced behavior in rats. Depress Anxiety 18:149-152.

Barberis C, Tribollet E (1996) Vasopressin and oxytocin receptors in the central nervous system. Crit Rev Neurobiol 10:119-154.

Barberis C, Balestre M-N, Jard S, Tribollet E, Arsenijevic Y, Dreifuss JJ, Bankowski K, Manning M, Chan WY, Schlosser SS, Holsboer F, Elands J (1995) Characterization of a novel, linear radioiodinated vasopressin antagonist: an excellent radioligand for vasopressin V1a receptors. Neuroendocrinology 62:135-146.

Berkman LF (1995) The role of social relations in health promotion. Psychosom Med 57:245-254.

Bielsky IF, Hu SB, Szegda KL, Westphal H, Young LJ (2004) Profound impairment in social recognition and reduction in anxiety-like behavior in vasopressin V1a receptor knockout mice. Neuropsychopharmacology 29:483-493.

Cassella JV, Davis M (1986) The design and calibration of a startle measurement system. Physiol Behav 36:377-383.

Champagne F, Diorio J, Sharma S, Meaney MJ (2001) Naturally occurring variations in maternal behavior in the rat are associated with differences in estrogen-inducible central oxytocin receptors. Proc Natl Acad Sci USA 98:12736-12741.

De Boer SF, Koolhaas JM (2003) Defensive burying in rodents: ethology, neurobiology and psychopharmacology. Eur J Pharmacol 463:145-161.

de Olmos JS, Heimer L (1999) The concepts of the ventral striatopallidal system and extended amygdala. New York: The New York Academy of Sciences.

Dunn AJ, Berridge CW (1990) Physiological and behavioral responses to corticotropin-releasing factor administration: is CRF a mediator of anxiety or stress responses? Brain Res Brain Res Rev 15:71-100.

Everts HG, Koolhaas JM (1999) Differential modulation of lateral septal vasopressin receptor blockade in spatial learning, social recognition, and anxiety-related behaviors in rats. Behav Brain Res 99:7-16.

Everts HG, De Ruiter AJ, Koolhaas JM (1997) Differential lateral septal vasopressin in wild-type rats: correlation with aggression. Horm Behav 31:136-144.

Francis DD, Young LJ, Meaney MJ, Insel TR (2002) Naturally occurring differences in maternal care are associated with the expression of oxytocin and vasopressin (V1a) receptors: gender differences. J Neuroendocrinol 14:349-353.

Giovenardi M, Padoin MJ, Cadore LP, Lucion AB (1997) Hypothalamic paraventricular nucleus, oxytocin, and maternal aggression in rats. Ann NY Acad Sci 807:606-609.

Giovenardi M, Padoin MJ, Cadore LP, Lucion AB (1998) Hypothalamic paraventricular nucleus modulates maternal aggression in rats: effects of ibotenic acid lesion and oxytocin antisense. Physiol Behav 63:351-359.

Goodson JL, Bass AH (2001) Social behavior functions and related anatomical characteristics of vasotocin/vasopressin systems in vertebrates. Brain Res Brain Res Rev 35:246-265.

Grigoriadis DE, Liu XJ, Vaughn J, Palmer SF, True CD, Vale WW, Ling N, De Souza EB (1996) ${ }^{125}$ I-Tyro-sauvagine: a novel high affinity radioligand for the pharmacological and biochemical study of human corticotropinreleasing factor 2 alpha receptors. Mol Pharmacol 50:679-686.

Haller J, Halasz J (1999) Mild social stress abolishes the effects of isolation on anxiety and chlordiazepoxide reactivity. Psychopharmacology (Berl) 144:311-315.

Haller J, Leveleki C, Baranyi J, Mikics E, Bakos N (2003) Stress, social avoidance and anxiolytics: a potential model of stress-induced anxiety. Behav Pharmacol 14:439-446.

Hammock EA, Young LJ (2002) Variation in the vasopressin V1a receptor promoter and expression: implications for inter- and intraspecific variation in social behaviour. Eur J Neurosci 16:399-402.

Hammock EA, Young LJ (2004) Functional microsatellite polymorphism associated with divergent social structure in vole species. Mol Biol Evol 21:1057-1063.

Hammock EA, Young LJ (2005) Microsatellite instability generates diversity in brain and sociobehavioral traits. Science 308:1630-1634.

Harmon AC, Huhman KL, Moore TO, Albers HE (2002) Oxytocin inhibits aggression in female Syrian hamsters. J Neuroendocrinol 14:963-969.

Hatch AM, Wiberg GS, Grice HC (1963) Long-term isolation stress in rats. Science 142:507.

Horwitz B, Soncrant TT, Haxby JV (1992) Covariance analysis of functional interactions in the brain using metabolic and blood flow data. In: Advances in metabolic mapping techniques for brain imaging of behavioral and learning functions (Gonzalez-Lima F, Finkenstadt T, Sheich H, eds). Boston: Kluwer Academic.

Insel TR (1992) Oxytocin—a neuropeptide for affiliation: evidence from behavioral, receptor autoradiographic, and comparative studies. Psychoneuroendocrinology 17:3-35.

Insel TR, Shapiro LE (1992) Oxytocin receptor distribution reflects social organization in monogamous and polygamous voles. Proc Natl Acad Sci USA 89:5981-5985.

Insel TR, Gelhard R, Shapiro LE (1991) The comparative distribution of forebrain receptors for neurohypophyseal peptides in monogamous and polygamous mice. Neuroscience 43:623-630.

Koolhaas JM, Everts H, de Ruiter AJ, de Boer SF, Bohus B (1998) Coping with stress in rats and mice: differential peptidergic modulation of the amygdala-lateral septum complex. Prog Brain Res 119:437-448.

Kosfeld M, Heinrichs M, Zak PJ, Fischbacher U, Fehr E (2005) Oxytocin increases trust in humans. Nature 435:673-676.

Lee Y, Davis M (1997) Role of the hippocampus, the bed nucleus of the stria terminalis, and the amygdala in the excitatory effect of corticotropinreleasing hormone on the acoustic startle reflex. J Neurosci 17:6434-6446.

Liang KC, Melia KR, Miserendino MJ, Falls WA, Campeau S, Davis M (1992) Corticotropin-releasing factor: long-lasting facilitation of the acoustic startle reflex. J Neurosci 12:2303-2312.

Liebsch G, Wotjak CT, Landgraf R, Engelmann M (1996) Septal vasopressin modulates anxiety-related behaviour in rats. Neurosci Lett 217:101-104.

Lim MM, Nair HP, Young LJ (2005) Species and sex differences in brain distribution of CRF receptor subtypes 1 and 2 in monogamous and promiscuous voles species. J Comp Neurol 487:75-92.

Lubin DA, Elliott JC, Black MC, Johns JM (2003) An oxytocin antagonist infused into the central nucleus of the amygdala increases maternal aggressive behavior. Behav Neurosci 117:195-201.

McIntosh AR, Lobaugh NJ (2004) Partial least squares analysis of neuroimaging data: applications and advances. NeuroImage 23 [Suppl 1]:S250-S263.

McIntosh AR, Rajah MN, Lobaugh NJ (1999) Interactions of prefrontal cortex in relation to awareness in sensory learning. Science 284:1531-1533.

Nair HP, Gonzalez-Lima F (2003) Large-scale networks in learning analyzed with partial least squares. In: Exploratory analysis and data modeling in functional neuroimaging (Sommer FT, Wichert A, eds). Cambridge, MA: MIT.

Nair HP, Berndt JD, Barrett D, Gonzalez-Lima F (2001) Maturation of extinction behavior in infant rats: large-scale regional interactions with medial prefrontal cortex, orbitofrontal cortex, and anterior cingulate cortex. J Neurosci 21:4400-4407.

Nemeroff CB (1988) The role of corticotropin-releasing factor in the pathogenesis of major depression. Pharmacopsychiatry 21:76-82.

Neumann ID, Torner L, Wigger A (2000) Brain oxytocin: differential inhibition of neuroendocrine stress responses and anxiety-related behaviour in virgin, pregnant and lactating rats. Neuroscience 95:567-575.

Odendaal JS, Meintjes RA (2003) Neurophysiological correlates of affiliative behaviour between humans and dogs. Vet J 165:296-301.

Petersson KM, Nichols TE, Poline JB, Holmes AP (1999) Statistical limitations in functional neuroimaging. I. Non-inferential methods and statistical models. Philos Trans R Soc Lond B Biol Sci 354:1239-1260.

Phelps SM, Young LJ (2003) Extraordinary diversity in vasopressin (V1a) receptor distributions among wild prairie voles (Microtus ochrogaster): patterns of variation and covariation. J Comp Neurol 466:564-576.

Phelps SM, Sharer CA, Young LJ (2002) Individual differences in vasopressin Vla receptors, promoter structure, and social behavior. Soc Neurosci Abstr 28:89.1.

Pitkow LJ, Sharer CA, Ren X, Insel TR, Terwilliger EF, Young LJ (2001) 
Facilitation of affiliation and pair-bond formation by vasopressin receptor gene transfer into the ventral forebrain of a monogamous vole. J Neurosci 21:7392-7396.

Pomeroy SL, Tamayo P, Gaasenbeek M, Sturla LM, Angelo M, McLaughlin ME, Kim JY, Goumnerova LC, Black PM, Lau C, Allen JC, Zagzag D, Olson JM, Curran T, Wetmore C, Biegel JA, Poggio T, Mukherjee S, Rifkin R, Califano A, et al. (2002) Prediction of central nervous system embryonal tumour outcome based on gene expression. Nature 415:436-442.

Primus RJ, Yevich E, Baltazar C, Gallager DW (1997) Autoradiographic localization of CRF1 and CRF2 binding sites in adult rat brain. Neuropsychopharmacology 17:308-316.

Ragnauth AK, Devidze N, Moy V, Finley K, Goodwillie A, Kow LM, Muglia LJ, Pfaff DW (2005) Female oxytocin gene-knockout mice, in a seminatural environment, display exaggerated aggressive behavior. Genes Brain Behav 4:229-239.

Rosner B (2006) Fundamentals of biostatistics, Ed 6. Belmont, CA: Thomson.

Ruis MA, te Brake JH, Buwalda B, De Boer SF, Meerlo P, Korte SM, Blokhuis HJ, Koolhaas JM (1999) Housing familiar male wildtype rats together reduces the long-term adverse behavioural and physiological effects of social defeat. Psychoneuroendocrinology 24:285-300.

Sanchez MM, Young LJ, Plotsky PM, Insel TR (1999) Autoradiographic and in situ hybridization localization of corticotropin-releasing factor 1 and 2 receptors in nonhuman primate brain. J Comp Neurol 408:365-377.

Schulz DW, Mansbach RS, Sprouse J, Braselton JP, Collins J, Corman M, Dunaiskis A, Faraci S, Schmidt AW, Seeger T, Seymour P, Tingley III FD, Winston EN, Chen YL, Heym J (1996) CP-154,526: a potent and selective nonpeptide antagonist of corticotropin releasing factor receptors. Proc Natl Acad Sci USA 93:10477-10482.

Sharp JL, Zammit TG, Azar TA, Lawson DM (2002) Stress-like responses to common procedures in male rats housed alone or with other rats. Contemp Top Lab Anim Sci 41:8-14.

Sommer FT, Wichert A, eds (2003) Large-scale networks in learning analyzed with partial least squares. Cambridge, MA: MIT.

Staiger JF, Nurnberger F (1989) Pattern of afferents to the lateral septum in the guinea pig. Cell Tissue Res 257:471-490.

Stern JA, Winokur G, Eisenstein A, Taylor R, Sly M (1960) The effect of group vs. individual housing on behaviour and physiological responses to stress in the ablino rat. J Psychosom Res 4:185-190.

Stevens J (1996) Applied multivariate statistics for the social sciences, Ed 3. Mahwah, NJ: Erlbaum.

Swerdlow NR, Geyer MA, Vale WW, Koob GF (1986) Corticotropinreleasing factor potentiates acoustic startle in rats: blockade by chlordiazepoxide. Psychopharmacology (Berl) 88:147-152.

Uchino BN, Garvey TS (1997) The availability of social support reduces cardiovascular reactivity to acute psychological stress. J Behav Med 20:15-27.

Walker DL, Davis M (1997) Double dissociation between the involvement of the bed nucleus of the stria terminalis and the central nucleus of the amygdala in startle increases produced by conditioned versus unconditioned fear. J Neurosci 17:9375-9383.

Wang Z, Young LJ (1997) Ontogeny of oxytocin and vasopressin receptor binding in the lateral septum in prairie and montane voles. Brain Res Dev Brain Res 104:191-195.

Wang Z, Zhou L, Hulihan TJ, Insel TR (1996) Immunoreactivity of central vasopressin and oxytocin pathways in microtine rodents: a quantitative comparative study. J Comp Neurol 366:726-737.

Wang Z, Young LJ, Liu Y, Insel TR (1997) Species differences in vasopressin receptor binding are evident early in development: comparative anatomic studies in prairie and montane voles. J Comp Neurol 378:535-546.

Watanabe M, Irie M, Kobayashi F (2004) Relationship between effortreward imbalance, low social support and depressive state among Japanese male workers. J Occup Health 46:78-81.

Whitfield CW, Cziko AM, Robinson GE (2003) Gene expression profiles in the brain predict behavior in individual honey bees. Science 302:296-299.

Wigger A, Sanchez MM, Mathys KC, Ebner K, Frank E, Liu D, Kresse A, Neumann ID, Holsboer F, Plotsky PM, Landgraf R (2004) Alterations in central neuropeptide expression, release, and receptor binding in rats bred for high anxiety: critical role of vasopressin. Neuropsychopharmacology 29:1-14.

Windle RJ, Shanks N, Lightman SL, Ingram CD (1997) Central oxytocin administration reduces stress-induced corticosterone release and anxiety behavior in rats. Endocrinology 138:2829-2834.

Winslow JT, Hastings N, Carter CS, Harbaugh CR, Insel TR (1993) A role for central vasopressin in pair bonding in monogamous prairie voles. Nature 365:545-548.

Young LJ, Wang Z (2004) The neurobiology of pair bonding. Nat Neurosci 7:1048-1054.

Young LJ, Winslow JT, Nilsen R, Insel TR (1997) Species differences in V1a receptor gene expression in monogamous and nonmonogamous voles: behavioral consequences. Behav Neurosci 111:599-605.

Young LJ, Wang Z, Insel TR (1998a) Neuroendocrine bases of monogamy. Trends Neurosci 21:71-75.

Young III WS, Shepard E, DeVries AC, Zimmer A, LaMarca ME, Ginns EI, Amico J, Nelson RJ, Hennighausen L, Wagner KU (1998b) Targeted reduction of oxytocin expression provides insights into its physiological roles. Adv Exp Med Biol 449:231-240.

Young LJ, Nilsen R, Waymire KG, MacGregor GR, Insel TR (1999) Increased affiliative response to vasopressin in mice expressing the V1a receptor from a monogamous vole. Nature 400:766-768. 